\title{
Role of the sympathetic nervous system in
}

\section{daunomycin-induced arrhythmia in the monkey}

\author{
B. BURKA, E. HERMAN AND J. VICK
}

Cancer Chemotherapy Department, Microbiological Associates Inc., 5221 River Road, Bethesda, Maryland 20016, U.S.A.

\section{Summary}

1. Infusion of daunomycin $50 \mathrm{mg} / \mathrm{kg}$ in the monkey consistently induced ventricular arrhythmias which were not influenced by bilateral vagotomy.

2. A central sympathetic component to the arrhythmias was suggested because spinal transection, ganglionic blockade or bilateral stellate ganglionectomy prevented any alterations in the e.c.g.

3. Bilateral adrenalectomy or splanchnic nerve section protected three of six animals. This source of catecholamines may not be necessary in every case to initiate the arrhythmia.

4. Guanethidine was a relatively ineffective antiarrhythmic agent. Timing appears to be important with this agent.

5. Pargyline, by monoamine oxidase inhibition or other mechanisms, significantly lowered the arrhythmic dose of daunomycin. Reserpine pretreatment, on the other hand, prevented any e.c.g. alterations following daunomycin.

6. Phenoxybenzamine exerted significant protection which may be related to its cardiodepressant properties.

7. Alterations in e.c.g. were seen in all (+)-propranolol pretreated animals, although the arrhythmic period was modified in two of three experiments. Racemic $( \pm)$-propranolol, which exerts direct myocardium depression as well as $\beta$-adrenoceptor blockade, was completely protective in four of five experiments. The results of the present experiments indicate that the sympathetic nervous system is intimately involved in the daunomycin arrhythmia.

\section{Introduction}

Daunomycin (NSC-82151) is an anthracycline antibiotic consisting of a pigmented aglycone (daunomycinone) in glycoside linkage with an amino sugar (daunosamine). This compound has induced a variety of cardiac abnormalities during the course of antileukaemic therapy (Tan, Tasaka, Yu, Murphy \& Karnofsky, 1967 ; Malpas \& Scott, 1969 ; Marmont, Damasio \& Rossi, 1969). Certain doses of daunomycin have recently been found to produce ventricular arrhythmias in hamsters and monkeys (Herman, Schein \& Farmar, 1969; Herman \& Vick, 1970). The latter experiments have demonstrated a possible involvement of the sympathetic nervous system in these arrhythmias. The present experiments were initiated to make a further assessment of the role of the sympathetic nervous system in the initiation of the daunomycin arrhythmia in the monkey. 


\section{Methods}

Fifty-seven male rhesus monkeys ( 2.5 to $3.5 \mathrm{~kg}$ ) were anaesthetized with $30 \mathrm{mg} / \mathrm{kg}$ pentobarbital sodium. The right femoral vein was cannulated for drug injection. Cannulas were also inserted into the right femoral artery and trachea for monitoring blood pressure (1 $\mathrm{mmHg} \equiv 1.333 \mathrm{mbar})$ and respiration. Needle-tipped electrodes were inserted subcutaneously into the appropriate limbs to record lead II e.c.g. Heart rate was determined by means of a cardiotach preamplifier. All recordings were made on a Hewlett-Packard polygraph.

\section{Pre-daunomycin surgery}

The influence of the sympathetic nervous system was altered by several surgical procedures. The vagi were severed in two experiments following separation from the carotid arteries. In five experiments the spinal cord was sectioned between the fourth and the fifth cervical vertebrae. The thorax cavity was opened before stellate ganglionectomy or section of the splanchnic nerves. In the former, the stellate ganglia, together with $3-4 \mathrm{~cm}$ of the sympathetic chain, were removed. The adrenal glands, in three animals, were removed following bilateral lumbar incisions. In all cases the animals were allowed to equilibrate 30 to $60 \mathrm{~min}$ before daunomycin injection.

\section{Pharmacological pretreatment}

The drugs utilized in the present experiments, the dosage calculated as the free base and the equilibration period before daunomycin administration, were as follows: normal saline ( $5 \mathrm{ml}, 10 \mathrm{~min})$; mecamylamine (Inversine) $(1.75 \mathrm{mg} / \mathrm{kg}, 10$ min); hexamethonium (10 mg/kg, $15 \mathrm{~min})$; guanethidine (Ismelin) (15 mg/ kg, $60 \mathrm{~min}$ ) ; pargyline (Eutonyl) $(10 \mathrm{mg} / \mathrm{kg}, 60 \mathrm{~min})$; phenoxybenzamine (Dibenzyline) $(5.0 \mathrm{mg} / \mathrm{kg}, 60 \mathrm{~min})$; ( \pm )-propranolol (Inderal) $(0.5 \mathrm{mg} / \mathrm{kg}, 10 \mathrm{~min})$; (+)-propranolol $(0.5 \mathrm{mg} / \mathrm{kg}, 10 \mathrm{~min})$; reserpine (Serpasil) $(2.5 \mathrm{mg} / \mathrm{kg}, 24 \mathrm{~h})$. These agents were either dissolved or diluted in normal saline so that the amount given was contained in a volume of $5 \mathrm{ml}$ or less. Each compound, except for phenoxybenzamine and reserpine, was injected over a 3 to $5 \mathrm{~min}$ period. Phenoxybenzamine infusion time was $30 \mathrm{~min}$ while reserpine was given intraperitoneally $24 \mathrm{~h}$ before the experiments.

Following the equilibrium period, daunomycin $(50 \mathrm{mg} / \mathrm{kg})$ was dissolved in $5 \mathrm{ml}$ of normal saline and injected over a 3 to $5 \mathrm{~min}$ period. In the pargyline experiments doses of 25 to $30 \mathrm{mg} / \mathrm{kg}$ daunomycin were utilized. The various physiological parameters were monitored for up to $60 \mathrm{~min}$ after daunomycin injection and then the experiment was terminated. When arrhythmias did appear, however, they were allowed to proceed until spontaneously reverting to sinus rhythm.

Control observations of the various physiological parameters were made just before either surgical or pharmacological pretreatment and again before administration of daunomycin. Changes in these parameters were also determined at the peak response following daunomycin, which normally occurred 5 to $15 \mathrm{~min}$ after injection. The mean and standard error of the mean (S.E.M.) were calculated when three or more values were obtained for each parameter. 
Results

\section{Saline control and bilateral vagotomy}

Daunomycin, $50 \mathrm{mg} / \mathrm{kg}$ intravenously, induced ventricular arrhythmias in nine of ten saline control animals. These results, together with the effect of daunomycin in the various surgical pretreatment experiments, are summarized in Table 1. A typical arrhythmic pattern induced by $50 \mathrm{mg} / \mathrm{kg}$ daunomycin is seen in Fig. 1. In this vagotomy experiment, as well as most others where arrhythmias did develop, a bigeminal pattern preceded a long-lasting repetitive sequence of ectopic foci. These e.c.g. irregularities were coincident with a slight hypotension and tachycardia. In most of the experiments emesis and flushing of the face were noted before the injection was complete.

The two vagotomized animals responded in nearly the same way to daunomycin as did the saline controls, except that during the arrhythmias both mean blood pressure and heart rate decreased slightly.

\section{Spinal transection}

Complete interruption of the spinal cord caused a prolonged decrease in both mean blood pressure and heart rate. The administration of daunomycin after $60 \mathrm{~min}$ produced relatively few changes in these parameters. Abnormalities in e.c.g. were observed in only one of the five spinal transected animals. The duration of the arrhythmia in this experiment was considerably less than in the saline controls.

\section{Bilateral stellate ganglionectomy}

This procedure, which involved opening the thoracic cavity, caused a sustained decrease in both blood pressure and heart rate. Daunomycin produced little further change in these parameters. Likewise, in both experiments the e.c.g. remained normal for up to $60 \mathrm{~min}$ after daunomycin.

\section{Bilateral splanchnic nerve section}

Section of the splanchnic nerves caused a consistent fall in both blood pressure and heart rate in one of the three experiments. Also, in only one experiment did the infusion of daunomycin produce an arrhythmia. The duration of this arrhythmia was slightly less than the saline controls.

\section{Bilateral adrenalectomy}

Surgical removal of both adrenal glands caused a slight hypotension and bradycardia. Infusion of daunomycin produced cardiac abnormalities in two of the three adrenalectomized animals which lasted for $60 \mathrm{~min}$. During these periods both blood pressure and, to a lesser extent, heart rate fell significantly below pre-injection levels.

\section{Mecamylamine and hexamethonium}

Both of these agents produced an almost immediate decrease in heart rate and blood pressure. Subsequent administration of daunomycin did not change the appearance of the e.c.g. in any of the experiments. This agent did, however, cause 


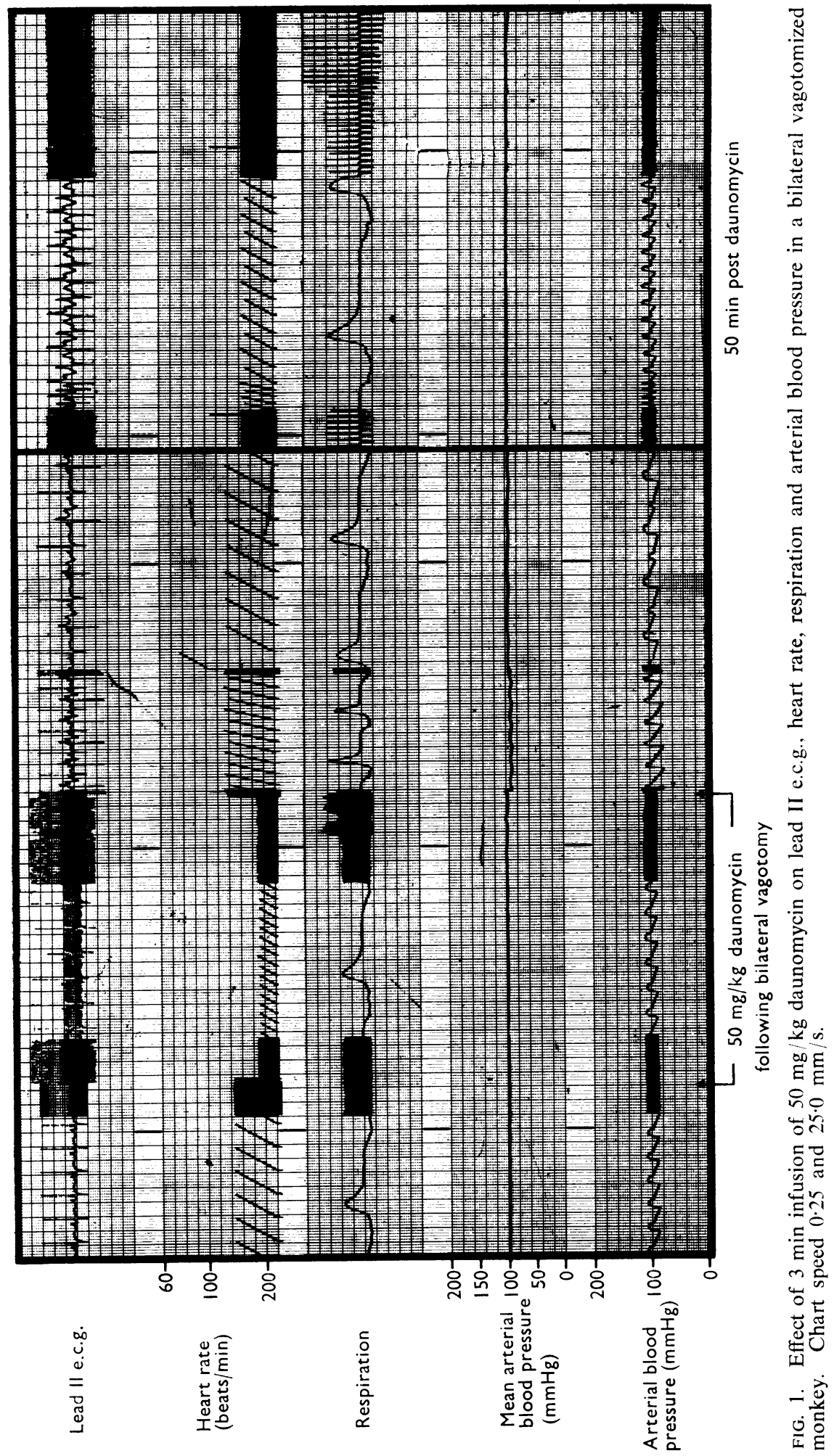




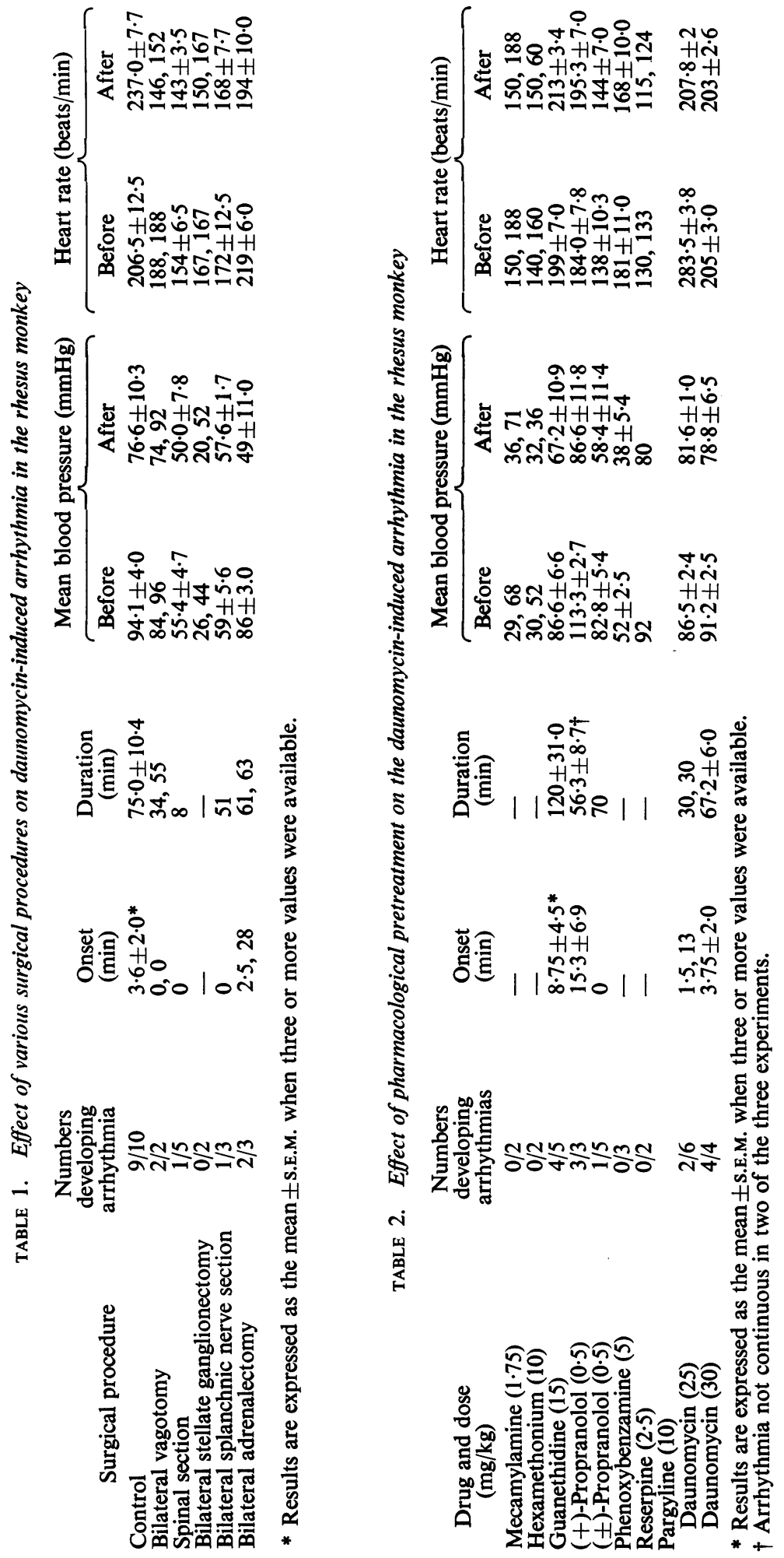


a slight hypertensive response in three of the four experiments and a tachycardia in the hexamethonium-pretreated animals. The results of all drug pretreatment experiments are summarized in Table 2.

\section{Guanethidine}

This sympathetic neuronal depressant produced an initial reversible hypotensive episode. The injection of daunomycin after $60 \mathrm{~min}$ produced abnormal e.c.g. patterns in four of the five experiments. The duration of these arrhythmias, as well as the simultaneous changes in blood pressure and heart rate, were comparable with the values obtained for the saline control animals.

\section{Phenoxybenzamine}

Phenoxybenzamine produced a decrease in arterial blood pressure in all three experiments. Heart rate was also depressed in two of the three experiments. $\alpha$-Adrenoceptor blockade was confirmed before the infusion of daunomycin by injection of adrenaline. Daunomycin caused a further moderate decline in blood pressure without any noticeable change in the e.c.g.

\section{( \pm )-Propranolol and (+)-propranolol}

Within $5 \mathrm{~min}$ of the injection of $0.5 \mathrm{mg} / \mathrm{kg}$ of $( \pm)$-propranolol, heart rate was significantly reduced and the typical cardiovascular responses to isoprenaline were inhibited. Heart rate was also decreased after (+)-propranolol but not to the same degree as by the racemic isomer.

The injection of daunomycin produced e.c.g. abnormalities in only one ( \pm )propranolol pretreated animal, although a moderate decrease in mean blood pressure was observed in all five experiments. Arrhythmias were seen in all three animals pretreated with (+)-propranolol. In two experiments the e.c.g. alterations were of 0.5 to $3 \mathrm{~min}$ duration and alternated with varying periods of sinus rhythm. Although the onset was delayed and the duration reduced these arrhythmias were similar in appearance to the saline controls.

\section{Reserpine}

The effect of $24 \mathrm{~h}$ reserpine pretreatment was determined in two experiments. Blood pressure was monitored in only one animal and found to be equivalent to the saline controls. Heart rate, however, was approximately $25 \%$ lower than the calculated saline control values. Daunomycin caused a slight hypotension and bradycardia but failed to alter the e.c.g. pattern in either of the two experiments.

\section{Pargyline}

This monoamine oxidase inhibitor was allowed to act for $60 \mathrm{~min}$ before the administration of daunomycin. During this period relatively little change was observed in either blood pressure or heart rate. Doses of daunomycin which normally would not cause arrhythmias were then infused. Daunomycin $(25 \mathrm{mg} / \mathrm{kg})$ induced cardiac abnormalities in two of six experiments while similar effects were noted in all four animals given $30 \mathrm{mg} / \mathrm{kg}$. These arrhythmias were equivalent in onset and duration to the saline controls. 


\section{Discussion}

The potential cardiac effects of daunomycin were not realized until this agent was used chronically in patients with acute leukaemia. During the course of therapy serious alterations were observed in both the e.c.g. and cardiac function (Tan et al., 1967 ; Malpas \& Scott, 1969 ; Marmont et al., 1969). Experimentally, acute cardiac toxicity was demonstrated in the Syrian golden hamster (Herman et al., 1969) and confirmed in the rhesus monkey (Herman \& Vick, 1970). The results of the present experiments demonstrate that the acute cardiac effects of daunomycin can be altered by surgical or pharmacological pretreatment of the autonomic nervous system. In these studies the sympathetic component appeared to play a predominant role, for bilateral vagotomy failed to prevent or alter the arrhythmia.

Daunomycin could conceivably alter sympathetic function in the midbrain or medullary areas since central application of certain compounds, such as digitalis glycosides (Bircher, Kanai \& Wang, 1963) and aconitine (Bhargava, Kohli, Sinha \& Tayal, 1969), have produced altered e.c.g. patterns. Boyajy \& Nash (1966) have found that either spinal cord transection or spinal anaesthesia protect against arrhythmias induced by systemic administration of ouabain. In the present experiments systemic administration of daunomycin produced not only e.c.g. alterations but also emesis in most of the animals. This latter action was almost certainly due to stimulation of the medullary chemoreceptor trigger zone. The fact that spinal section and ganglionic blockade prevented the arrhythmia seems to indicate that central sympathetic centres do contribute to the cardiac toxicity induced by daunomycin.

Recently Ten Eick \& Hoffman (1969) have shown that systemic injection of ouabain increased the tension developed by the nictitating membrane to constant current, constant voltage, stimulation of the preganglionic or postganglionic nerves. They attribute this action to an increase in excitability of the nerves. In the present experiments, however, both bilateral stellate ganglionectomy and ganglionic blockade prevented e.c.g. alterations, indicating that if daunomycin acts in a similar manner it must do so at preganglionic or higher levels.

Bilateral adrenalectomy or splanchnic nerve section protected three of six animals against daunomycin toxicity. Why these animals are not all protected is not entirely clear, for previous studies have shown that plasma adrenaline levels are elevated following an arrhythmic dose of daunomycin (Herman \& Vick, 1970). Perhaps in certain animals direct sympathetic stimulation of the heart through the stellate ganglia is not enough and the increase in plasma levels of adrenaline induced directly or indirectly by daunomycin tips the balance toward cardiac dysfunction.

It appears that one dominant factor in the induction of arrhythmias by daunomycin is the presence of catecholamines either from direct cardiac nerve stimulation or elevated plasma levels from the adrenal medulla. Previous experiments have shown that injections of adrenaline in animals not initially developing arrhythmias following daunomycin, or excitation of an unanaesthetized animal treated with daunomycin, induced long-lasting periods of e.c.g. abnormalities (Herman \& Vick, 1970). At the myocardial level both adrenaline and ouabain have been shown to enhance diastolic depolarization in Purkinje fibres and adjacent ventricular areas (Han \& Moe, 1964 ; Hoffman \& Singer, 1964). The arrhythmogenic property of these compounds might be due to a positive chronotropic action in potential pace- 
maker tissue (West, 1963). It has not as yet been determined whether daunomycin exerts a similar direct myocardial action. Daunomycin, however, has been found to cause a profound constriction of the coronary vasculature and eventually lead to failure of the isolated dog heart (Herman \& Vick, 1970). Presumably such an action in the intact animal could compromise the coronary blood supply and lead to myocardial anoxia. The arrhythmic threshold to sympathetic stimulation is lowered considerably by myocardial anoxia (Hoffman \& Cranefield, 1964).

Guanethidine, an adrenergic neuronal depressant, was relatively ineffective in protecting against the daunomycin toxicity. This agent has been found to interfere with release of catecholamines following nerve stimulation as well as deplete stores of catecholamines (McCubbin, Kaneko \& Page, 1961 ; Cass, Kuntzman \& Brodie, 1960). Apparently timing is important with this agent. The arrhythmic dose of ouabain was significantly increased when guanethidine was given $24 \mathrm{~h}$ beforehand (Raines, Moros \& Levitt, 1968). On the other hand, bretylium lowered the arrhythmic dose if given just before ouabain administration, while a $4 \mathrm{~h}$ pretreatment had no effect on the toxic dose. Bhagat \& Shideman (1963) found that within $2 \mathrm{~h}$ of guanethidine administration catecholamine levels in the rat heart were significantly decreased. Since, in the present experiments, daunomycin was injected $60 \mathrm{~min}$ following guanethidine it is possible that any protective effects of sympathetic neuronal depression were negated by a concomitant release of catecholamines.

Reserpine and pargyline exerted opposite effects on the daunomycin arrhythmia. The arrhythmic dose of daunomycin in the pargyline-pretreated animals was significantly lower than the control animals. This sensitization must be ascribed to other than a direct action, because pargyline did not appear to exert any intrinsic sympathomimetic action. This agent has been reported to increase both brain and superior cervical ganglia catecholamine concentrations in cats and increase myocardial catecholamines in rats (Schoepke \& Wiegand, 1963). Since pargyline was not given to spinal or bilateral stellate ganglionectomized animals it was not possible to determine the most important level of action. However, a lower dose of daunomycin might be able to initiate arrhythmias if the effective levels of catecholamines acting on myocardial tissues are elevated by release or decreased metabolism.

Reserpine pretreatment, which prevented any e.c.g. alterations, has also been found to protect against digitalis glycoside arrhythmias (Boyajy \& Nash, 1965 ; Ciofalo, Levitt \& Roberts, 1966). Reynolds \& Horne (1969) found that, in addition to pretreatment, some cardiac protection was afforded animals given reserpine just before ouabain. In addition, these investigators found that tetrabenazine, a compound with central effects similar to reserpine but without depletion of cardiac catecholamines, increased the cardiotoxic dose of ouabain to an amount similar to that where reserpine was given just before ouabain. These results tend to indicate that reserpine protection against ouabain toxicity could occur at both a central and peripheral level. In the present experiments, in which only $24 \mathrm{~h}$ pretreated animals were used, such a dual action would also be expected to protect against the daunomycin-induced arrhythmia.

Drugs which directly antagonize the actions of catecholamines on the effector organs were found to protect against the daunomycin arrhythmia. Previous studies have shown that phenoxybenzamine is an effective antiarrhythmic drug against adrenaline-induced arrhythmias during cyclopropane anaesthesia (Moe, Malton, Rennick \& Freyburger, 1948). The mechanism of action appears to involve both 
an inhibition of blood pressure elevation and direct myocardial depression (Nickerson \& Smith, 1949). This latter action might be responsible for the protection in the present experiments, since little or no change in blood pressure was observed.

The $\beta$-adrenoceptor antagonist ( \pm )-propranolol prevented e.c.g. abnormalities in four of five experiments. This agent has been shown to antagonize the myocardial actions of catecholamines (Shanks, 1966). Such an action could be responsible for the protection seen in the present experiments. However, besides $\beta$-adrenoceptor antagonism, ( \pm )-propranolol also has direct myocardial depressant properties (Morales-Aguilera \& Vaughan-Williams, 1965). The dextro form of propranolol, on the other hand, exerts similar cardiodepressant properties with little $\beta$-adrenoceptor blocking action (Howe \& Shanks, 1966). This agent did not prevent the appearance of arrhythmias in any of three experiments, although in two animals the e.c.g. alterations were both delayed in onset and decreased in intensity. Thus direct myocardial depression does afford some protection against daunomycin-induced cardiotoxicity, but this property is enhanced if $\beta$-adrenoceptor antagonism occurs simultaneously. These results, together with others described in the present experiments, indicate that the sympathetic nervous system is intimately involved in the ventricular arrhythmias induced by daunomycin.

This work was supported by Contract PH 43-68-1283, with Chemotherapy, National Cancer Institute, National Institutes of Health.

\section{REFERENCES}

Bhagat, B. \& Shideman, F. E. (1963). Mechanism of the positive inotropic responses to bretylium and guanethidine. Br. J. Pharmac. Chemother., 20, 56-62.

Bhargava, K. P., Kohli, R. P., Sinha, J. N. \& Tayal, G. (1969). Role of catecholamines in centrogenic cardiac arrhythmia induced by aconitine. Br. J. Pharmac., 36, 240-252.

Bircher, R. P., Kanai, T. \& Wang, S. C. (1963). Mechanism of cardiac arrhythmias and blood pressure changes induced in dogs by pentylenetetrazol, picrotoxin and deslanoside. J. Pharmac. exp. Ther., 141, 6-14.

BoyAJY, L. D. \& NASH, C. B. (1965). Influence of reserpine on arrhythmias, inotropic effects and myocardial potassium balance induced by digitalis materials. J. Pharmac. exp. Ther., 148, 193-201.

BoyAJY, L. D. \& NASH, C. B. (1966). Alteration of ouabain toxicity by cardiac denervation. Tox. appl. Pharmac., 9, 109-208.

Cass, R., Kuntzman, R. \& Brodie, B. B. (1960). Norepinephrine depletion as a possible mechanism of action of guanethidine, a new hypotensive agent. Proc. Soc. exp. Biol. Med., 103, 871-872.

Ciofalo, F., LevitT, B. \& Roberts, J. (1966). Some aspects of the antiarrhythmic activity of reserpine. Br. J. Pharmac. Chemother., 28, 44-50.

HAN, J. \& MOE, G. K. (1964). Nonuniform recovery of excitability in ventricular muscle. Circulation Res., 14, 44-60.

Herman, E. H., Schein, P. \& Farmar, R. M. (1969). Comparative cardiac toxicity of daunomycin in three rodent species. Proc. Soc. exp. Biol. Med., 130, 1098-1102.

Herman, E. H. \& VICK, J. A. (1970). The acute pharmacological actions of daunomycin in the dog and monkey. Pharmacology, 3, in the Press.

Hoffman, B. F. \& Cranefield, P. F. (1964). The physiological basis of cardiac arrhythmias. Am. J. Med., 37, 670-695.

Hoffman, B. F. \& Singer, D. H. (1964). Digitalis on the electrical activity of cardiac fibers. Prog. Cardiovascular Diseases, 7, 226-260.

Howe, R. \& Shanks, R. G. (1966). Optical isomers of propranolol. Nature, Lond., 210, $1336-1337$.

Malpas, J. S. \& ScotT, R. B. (1969). Daunorubicin in acute myelocytic leukaemia. Lancet, 1 (7592), $469-470$.

Marmont, A. N., Damasio, E. \& Rossi, F. (1969). Cardiac toxicity of daunorubicin. Lancet, 1 (7599), 837-838.

McCubbin, J. W, Kaneko, Y. \& Page, I. H. (1961). The peripheral cardiovascular actions of guanethidine in dogs. J. Pharmac. exp. Ther., 131, 346-354.

Moe, G. M., Malton, S. D., Rennick, R. B. \& Freyburger, E. A. (1948). The role of arterial pressure in the induction of idioventricular rhythms under cyclopropane anesthesia. J. Pharmac. exp. Ther., 94, 319-327. 
Morales-Agullera, A. \& Vaughan Williams, E. M. (1965). The effects on cardiac muscle of beta adrenergic anatagonists in relation to their activity as local anaesthetics. Br. J. Pharmac. Chemother., 24, 332-338.

Nickerson, M. \& SMITH, S. M. (1949). Protection against cyclopropane-epinephrine arrhythmias by dibenamine and other agents. Anesthesiology, 10, 562-576.

RaINes, A., Moros, D. \& LevitT, B. (1968). The effect of guanethidine on ouabain induced ventricular arrhythmias in the cat. Archs int. Pharmacodyn. Thér., 174, 373-377.

Reynolds, A. K. \& Horne, M. L. (1969). Studies on the cardiotoxity of ouabain. Can. J. Physiol., 47, 165-170.

SchöPKe, H. G. \& WIEGAND, R. G. (1963). Relation between norepinephrine accumulation or depletion and blood pressure response in the cat and rat following pargyline administration. Ann. N.Y. Acad. Sci., 107, 924-934.

Shanks, R. G. (1966). The effect of propranolol on the cardiovascular responses to isoprenaline, adrenaline and noradrenaline in the anaesthetized dog. Br. J. Pharmac. Chemother., 26, 322-333.

Tan, C., Tasaka, H., YU, K-P., MurPhy, M. L. \& Karnofsky, D. A. (1967). Daunomycin, an antitumor antibiotic, in the treatment of neoplastic disease. Clinical evaluation with special reference to childhood leukemia. Cancer, 20, 333-353.

TEN EICK, R. E. \& HoffMan, B. F. (1969). The effect of digitalis on the excitability of autonomic nerves. J. Pharmac. exp. Ther., 169, 95-108.

West, T. C. (1963). In Pharmacology of Cardiac Function, vol. 5, Second International Pharmacological Meeting, Prague, pp. 133-139. London: Pergamon.

(Received March 3, 1970) 